Geopolítica(s) Revista de estudios sobre espacio y poder ISSN: 2172-3958

https://dx.doi.org/10.5209/geop.71202

\title{
La Gestión por Cuenca en Costa Rica: genealogía y trayectoria de un concepto $^{1}$
}

\author{
Tania Rodríguez Echavarría ${ }^{2}$
}

Recibido: 25 de agosto de 2020 / Aceptado: 30 de junio de 2021

Resumen. La Gestión Integrada del Recurso Hídrico (GIRH) así como la gestión por cuenca son conceptos y discursos que se difundieron e internacionalizaron desde la década de los años noventa. Organizaciones internacionales y el Banco Mundial promovieron la adecuación de las legislaciones nacionales a la luz de estos conceptos, presentándolos como la respuesta ideal a los problemas que enfrentaba el agua. El presente artículo, busca analizar la genealogía de estos conceptos, así como su aceptación casi generalizada por parte de gobiernos, de organismos internacionales y de académicos. Lo cual permitió que se convirtieran en un discurso hegemónico prácticamente incuestionable. Sin embargo, existen importantes críticas, las cuales advierten que estos conceptos no son neutrales y/o científicos, sino que son una decisión, una construcción política occidental y neoliberal. Con el fin de comprender como se aplicaron los conceptos GIRH y de gestión por cuenca en Costa Rica, se emprendió un proceso de investigación que implicó una importante revisión bibliográfica y de literatura gris de proyectos y de programas que promueven la GIRH. Además, se realizaron entrevistas a expertos, académicos, funcionarios públicos y a actores locales relacionados con el sector del agua.

Palabras clave: Gestión Integrada del Recurso Hídrico; cuencas; comunidades epistémicas del agua; hidro-hegemonía; discursos institucionales autorizados.

\section{[en] Management by Basin in Costa Rica: Genealogy and Trajectory of a Concept}

\begin{abstract}
Integrated Water Resource Management (IWRM) as well as basin management are concepts and discourses that have been disseminated and internationalized since the 1990s. International organizations and the World Bank promoted the adaptation of national legislation in light of these concepts, presenting them as the ideal answer to the problems regarding water. This article seeks to analyze the genealogy of these concepts, as well as their almost general acceptance by governments, international organizations and academics. This allowed them to become a practically unquestionable hegemonic discourse. However, there are important critics, which warn that these concepts are not neutral and / or scientific, but they are a decision, a western and neoliberal political construction. In order to understand how the IWRM and basin management concepts were applied in Costa Rica, a research process that involved an important bibliographic and gray literature review of projects and programs that promote
\end{abstract}

1 Titulo inspirado por el artículo de Stéphane Giotti: "Le bassin transfrontelier: emergence, construction et intinéraire d'un concept", publicado en el 2012 en la revista Regions and cohesions.

2 Escuela de Ciencias Políticas, Escuela de Geografía y Directora del Posgrado Centroamericano de Ciencias Políticas, Universidad de Costa Rica.

Email: tania.rodriguezechavarria@ucr.ac.cr

https://orcid.org/0000-0001-5476-1575 
IWRM was undertaken. In addition, interviews were conducted with experts, academics, public officials and local actors related to the water sector.

Keywords: Integrated Management of Water Resources; basins; epistemic communities of water; hydro-hegemony; authorized institutional speeches.

\section{[pt] Gestão por Bacia na Costa Rica: genealogia e trajetória de um conceito}

Resumo. A Gestão Integrada de Recursos Hídricos (GIRH), bem como a gestão de bacias, são conceitos e discursos que foram disseminados e internacionalizados desde a década de 1990. Organizações internacionais e o Banco Mundial promoveram a adaptação da legislação nacional à luz desses conceitos, apresentando-os como a resposta ideal aos problemas relacionados à água. Este artigo busca analisar a genealogia desses conceitos, bem como sua aceitação quase geral por governos, organizações internacionais e acadêmicos. Isto permitiu que se tornassem um discurso hegemônico praticamente indiscutível. No entanto, há críticas importantes, que alertam que esses conceitos não são neutros e/ou científicos, mas sim uma decisão, uma construção política ocidental e neoliberal. A fim de compreender como os conceitos de GIRH e gestão de bacias foram aplicados na Costa Rica, foi realizado um processo de pesquisa que envolveu uma vasta revisão bibliográfica e de literatura cinzenta de projetos e programas que promovem a GIRH. Além disso, foram realizadas entrevistas com especialistas, acadêmicos, funcionários públicos e atores locais relacionados com o setor hídrico.

Palavras-chave: Gestão Integrada de Recursos Hídricos; bacias; comunidades epistêmicas de água; hidro-hegemonia; discursos institucionais autorizados.

Sumario. Introducción. 1. El surgimiento e internacionalización de la Gestión Integrada del Recurso Hídrico y de la gestión por cuencas hidrográficas. 2. Legislación e la institucionalidad del Agua en Costa Rica. 3. ¿La GIRH, una respuesta occidental y un discurso hegemónico? 4. La cuenca hidrográfica, la voluntad de inventar un territorio. 4.1. La gestión por cuenca, una construcción social y política. 4.2. Las cuencas hidrográficas frente a la coexistencia de "otros" territorios. 5. Los limites del discurso de la GIRH y la gestión por cuenca. 5.1. ¿La GIRH, un discurso inaplicable? 5.2. La GIRH y la gestión por cuenca un "discurso institucional autorizado". 5.3. Estabilización de datos. 5.4. La invisibilización de la conflictividad, un discurso sin adversarios. Conclusiones. Referencias.

Cómo citar: Rodríguez Echavarría, T. (2021). La Gestión por Cuenca en Costa Rica: genealogía y trayectoria de un concepto. Geopolítica(s). Revista de estudios sobre espacio y poder, 12(2), 277-304. https://dx.doi.org/10.5209/geop.71202

\section{Introducción}

Analizar la genealogía de un concepto nos permite entender como las ideas circulan de un grupo a otro y de un país a otro. Pero también nos ayuda a esclarecer quienes son los responsables de la concepción de un concepto, como este se aplica y quiénes son los actores que lo impulsan. Además, estudiar su trayectoria nos permite determinar cuales son los intereses que hay detrás de su difusión e internacionalización.

La gestión por cuenca fue introducida en el siglo XVII por el cartógrafo y geógrafo francés Philippe Buache (1700-1773) con el objetivo de generar una delimitación "objetiva" de las regiones. Buache definió la cuenca hidrográfica, como una porción del territorio delimitada por las líneas de cresta, cuyas aguas fluyen hacia el mar o hacia otro río (Ghiotti, 2007, p.6). A pesar de su antigüedad este concepto no se vuelve global hasta la década de los años 1990. Su internacionalización se da junto con la difusión de la Gestión Integrada de Recurso Hídrico (GIRH) por parte de 
organismos internacionales como lo fue Global WaterPartnership (GWP), la Organización de Estados Americanos (OEA), la Unión Internacional para la Conservación de la Naturaleza (UICN) y el Banco Mundial. En Centroamérica, el Sistema de Integración Centroamericano (SICA) a través de su Comisión Centroamericana de Ambiente y Desarrollo (CCAD tendrá también un rol protagónico. Progresivamente estas nociones fueron introducidas en las legislaciones de agua en el mundo y se convirtieron en conceptos prácticamente indiscutibles.

El presente artículo busca estudiar el origen de este concepto y su trayectoria, con el objetivo de entender desde donde fue pensado y quienes fueron sus principales defensores. Además, se analizará cuales han sido las estrategias de transferencia de estos conceptos (proyectos, programas, prestamos) y cuál ha sido su efectividad y su aplicabilidad, prestando especial atención en el caso costarricense. Esto debido a que este país evidencia importantes contradicciones, por un lado, se presenta a escala mundial como "la excepción verde" del Istmo Centroamericano por su gestión de áreas protegidas, su inversión en energía renovable (hidroeléctricas), el desarrollo de sistemas de pagos por servicios ambientales y más recientemente por el lobby internacional que ha ejercido para hacerle frente al cambio climático. Y, por otro lado, ha promovido un modelo de desarrollo agro-exportador, el cual necesita de una legislación poco restrictiva en materia de agua que permita al sector agropecuario tener acceso a grandes volúmenes de agua a bajo costo. En la actualidad este sector ha sido el principal detractor para introducir la GIRH en el país. Es así como en Costa Rica hoy en día no existe una legislación actualizada, acorde a las necesidades actuales que tiene el sector hídrico.

De esta forma, nos interesaremos en las principales limitaciones en cuanto la aplicabilidad de la GIRH y la gestión por cuenca en Costa Rica, recuperando las importantes reflexiones que desde la literatura se ha generado sobre los países del Sur global, en donde coexisten otros "territorios" y modelos productivos que han obstaculizado las acciones de GIRH. También se realizará un análisis del discurso de las fórmulas de la GIRH y de la gestión por cuenca, que categorizamos como un tipo de "discurso institucional autorizado", el cual busca legitimarse y convertirse en un eslogan prácticamente incuestionable.

Este artículo presenta los resultados de un proceso de investigación iniciado en el marco de una tesis doctoral (Rodríguez, 2014) y continuado a través del proyecto "Gestión por cuenca, genealogía e itinerario de un concepto", el cual se ha desarrollado desde el Observatorio del Agua y el Cambio Global de la Universidad de Costa Rica desde el 2018. Desde el punto de vista metodológico, este ha sido un proceso de investigación cualitativo e interdisciplinario que articuló métodos y técnicas propias de la geografía y la ecología política. Todo esto, con el fin de comprender las complejas relaciones de poder que se dan alrededor de las comunidades epistémicas del agua y entre la gran diversidad de actores que participan a diferentes escalas en su gestión. Para esto se acudió a varias técnicas de investigación como la revisión documental y bibliográfica, la observación participante (en reuniones, paneles y talleres ligados a la gestión del agua en Centroamérica y Costa Rica) y la realización de entrevistas a profundidad semi-estructuradas en Costa Rica a funcionarios públicos, hidrólogos, geógrafos, expertos y cooperantes en materia de agua, así como a actores locales como representantes de asociaciones que administran los acueductos locales (ASADAS), ecologistas, productores, líderes indígenas, entre otros. 
De esta forma, este artículo aspira a generar una reflexión alrededor de la genealogía, circulación y aplicación de la GIRH y de la gestión por cuenca. Analizando como estos conceptos y metodologías se han materializando en geografías nacionales.

\section{El surgimiento e internacionalización de la Gestión Integrada del Recurso Hídrico y de la gestión por cuencas hidrográficas}

Según Molle, desde finales del siglo XIX hasta los años 90, la búsqueda de soluciones a los problemas ligados a la gestión de los recursos hídricos estuvo dominada por enfoques "que le daban prioridad a la ingeniería y a las grandes infraestructuras hidráulicas" (Molle, 2012b, p.23). Desde esta perspectiva, los Estados fueron los principales responsables de la aplicación de lo que F. Molle llama "la misión hidráulica", heredera de los grandes desarrollos hidráulicos coloniales (Molle, 2012b, p.23). Este modelo, que S. Ghiotti llama el tríptico Frontera/Estado/Navegación, percibe los cursos de agua, por un lado, como problemáticas políticas cuya resolución es responsabilidad de los Estados, los cuales afirman su soberanía sobre ellos. Y por otro lado, estos recursos se conciben como elementos sujetos a intereses económicos debido a su papel en la circulación de personas y bienes (Ghiotti, 2014, pp.19-20).

Cabe señalar que este modelo de desarrollo ${ }^{3}$, que tuvo un profundo impacto en la planificación y en el ordenamiento de las cuencas durante las décadas de 1970 a 1980, fue fuertemente promovido y financiado por el Banco Mundial (Ghiotti, 2014, p.18).

Este fenómeno es observable en Costa Rica a través de la evolución de las instituciones que gestionan el agua. Según José Miguel Zeledón (Comunicación personal, 21 de agosto del 2020) director de la Dirección de Aguas (DINA) del Ministerio de Ambiente y Energía de Costa Rica, "si uno ve la ley de Aguas de 1942 de Costa Rica, el tema central era la energía". Esto debido a que el agua era gestionada desde el Departamento de Aguas del Servicio Nacional de Electricidad por su importancia en la generación de energía hidroeléctrica.

Sin embargo, a partir de finales de los años 1980, podemos observar un cambio de paradigma en las "redes internacionales y las comunidades epistémicas de agua" (Julien, 2012, p.2). Este cambio de paradigma se debe a la toma de conciencia mundial de que muchos recursos naturales (especialmente el agua) no son renovables. Se da en un contexto en donde se cuestiona la reducción de la biodiversidad y se empieza a evidenciar la amenaza que representa el cambio climático.

La comunidad epistémica del agua ${ }^{5}$ llega a la conclusión en la década de los noventa de que el agua se encuentra sobreexplotada debido al crecimiento económico y demográfico, situación que provoca una escasez que puede dar lugar a conflictos o "guerras por el agua" (Ghiotti, 2014; Julien, 2012).

\footnotetext{
Los primeros desarrollos hidráulicos fueron llevados a cabo por los Estados Unidos en 1930, al igual que todo el sistema de presas en el río Tennessee, administrado por la Autoridad del Valle del Tennessee (TVA).

4 El término "comunidad de agua epistémica" es utilizado por F. Molle, S. Ghiotti y F. Julien (Ghiotti, 2014; Julien, 2012; Molle, 2012)

5 La comunidad epistémica del agua está compuesta por: funcionarios internacionales y nacionales, industriales, expertos, científicos, ONG, OIG, entre otros (Ghiotti, 2014, p.21).
} 
Según, S. Ghiotti, este discurso de las guerras del agua, produjo una importante producción de estudios sobre el estado de los recursos hídricos y de las cuencas (Ghiotti, 2014, p.17). Es así que entre finales de los años 1980 y los 1990, a escala mundial, se produjo un cambio gradual de paradigma en la percepción de la naturaleza y la gestión del agua, que se materializó en las redes internacionales de profesionales del agua (Julien, 2012, p.4) y se concretó en el Informe Brundtland, también conocido como "Nuestro futuro en común". Este informe, que apareció en 1987, cuestionó el modelo de desarrollo tradicional basado sólo en el crecimiento económico e introdujo la retórica del desarrollo sostenible (Ghiotti, 2014; Molle, 2012b). Según este informe, el desarrollo sostenible promueve reivindicaciones ambientales y sociales y busca conciliar el desarrollo económico con la sostenibilidad social y ambiental para las nuevas generaciones (WCED, 1987).

Es en este contexto, que surge el concepto de Gestión Integrada de los Recursos Hídricos (GIRH), tras la Conferencia Internacional sobre el Agua y el Medio Ambiente $^{6}$, celebrada en Dublín en enero de 1992. Es durante esta conferencia que se promueve la GIRH como la principal respuesta a los desafíos de un sector hídrico "caótico" debido a la gestión históricamente fragmentada del agua (Julien, 2012, p.5; Molle, 2012a, p.21). Es así que se redacta la Declaración de Dublín, la cual establece cuatro principios para guiar "la gobernabilidad del agua y la puesta en marcha de la GIRH" (Julien, 2012, p.5), los cuales son: 1) el agua dulce es un recurso finito y vulnerable, esencial para la vida, el desarrollo y el medio ambiente; 2) el aprovechamiento y la gestión del agua debe inspirarse en un planteamiento basado en la participación de los usuarios, los planificadores y los responsables de las decisiones a todos los niveles; 3) la mujer desempeña un papel fundamental en el abastecimiento, la gestión y la protección del agua, y 4) el agua tiene un valor económico en todos sus diversos usos en competencia a los que se destina y debería reconocérsele como un bien económico (ICWE, 1992).

Esta conferencia de expertos ${ }^{7}$ influyó en el desarrollo y la práctica de la GIRH e introdujo de forma muy general la gestión por cuenca hidrográfica y subrayó la importancia de la participación de los usuarios, los planificadores y los decisores en los procesos de toma de decisión. También incluye el enfoque de género en la gestión del agua y destaca la dimensión económica del agua. Este último aspecto ha sido muy discutido, ya que esta declaración "incluye al agua en la categoría de los productos comerciales", haciéndose así eco de los principios del consenso de Washington, que "aboga por la rentabilidad de las inversiones públicas, que impone la regla de que lo que tiene un costo, debe tener un precio" (Bouquet, 2012, p.63). De esta manera, a nivel internacional se toma una posición ideológica clara, puesto que se renuncia así al principio de declarar el agua como un bien público y universal.

La referencia a los principios de la Declaración de Dublín es, pues, necesaria porque permite comprender bajo qué influencia ideológica se ha concebido la GIRH

6 La conferencia reunió a más de 500 expertos nombrados por los gobiernos de unos 100 países y a representantes de 80 organizaciones internacionales, intergubernamentales y no gubernamentales (ICWE, 1992; Julien, 2012, p.5).

7 Sin embargo, cabe señalar que aunque la Conferencia de Dublín es a menudo denominada como la primera conferencia que se refiere a la GIRH, M. Rahaman y O. Varis hacen referencia a la Conferencia sobre el Agua de 1977 en Mar del Plata, como una de las primeras reuniones internacionales que establecieron un plan de acción sobre la GIRH y que abarcó una amplia gama de aspectos como el uso y la eficiencia del agua, el medio ambiente, la salud, la contaminación, la planificación de políticas y la cooperación internacional (Rahaman y Varis, 2005, p.16). 
y, posteriormente, cómo influyen esos principios en el discurso y el contenido de los proyectos que aspiran a poner en práctica acciones de GIRH.

La crítica más importante a la Conferencia de Dublín fue la falta de participación activa de los expertos y representantes de los países en vías de desarrollo (Rahaman y Varis, 2005, p.16). Muchos profesionales del agua y políticos del Sur criticaron también el principio 4 y reclamaron que estos principios no estaban tomando en cuenta el complejo escenario del agua en los países en vías de desarrollo lo cual podría dificultar su aplicabilidad (Rahaman y Varis, 2005).

A raíz de la Declaración de Dublín en la Cumbre de la Tierra de Río de Janeiro en junio de 1992, la GIRH se definió como: "Un proceso que promueve el desarrollo y la gestión coordinada del agua, la tierra y los recursos conexos, con miras a maximizar el bienestar económico y social de manera equitativa, sin comprometer la sostenibilidad de los ecosistemas vitales" (GWP, 2000, p.24). Esta cumbre también pondrá en marcha un plan de acción llamado Agenda 21, que dedicará su capítulo 18 al agua, determinando que la GIRH "se basa en la idea de que el agua es parte integral del ecosistema y es un recurso natural, un bien social y económico cuya cantidad y grado determinan su uso" (ONU, 1992).

En Costa Rica es en este contexto que a finales de la década de los años 1990 se traslada el Departamento de Aguas al Ministerio de Ambiente y Energía y en el año 2010 este departamento se convierte en la Dirección de Aguas (DINA).

El concepto de GIRH según F. Molle abarca los tres principios del desarrollo sostenible, es decir, la eficiencia (racionalidad económica), la equidad y el medio ambiente (Molle, 2012b, p.25). La Figura 1 presenta estos "tres pilares" de la GIRH y las acciones claves propuestas para lograrlos.

El estudio de los elementos que componen la GIRH revela que este modelo hace hincapié en las nociones de eficiencia, mercados ecológicos, privatización de servicios, entre otras. Para comprender esta influencia neoliberal, es necesario contextualizar la aparición de la GIRH en el período de apogeo de los programas de ajuste estructural (PAE), que fomentaron la reducción sistemática del papel del Estado, en particular en los sectores de salud, educación y en los servicios públicos. Debido a que los Estados fueron considerados ineficientes y responsables de la crisis del agua, debido a "su mala gestión".

En respuesta a la ineficiencia de los Estados, la GIRH propone una mayor participación del sector privado y la transferencia de múltiples responsabilidades a los usuarios (Molle, 2012b, p.26). Es así como la GIRH está fuertemente influenciada por la ideología neoliberal, por lo que no es de extrañar que proponga introducir los intereses privados en los procesos de gestión del agua.

Otro aspecto importante es que la GIRH introduce la noción de "cuenca hidrográfica" como "la unidad de gestión más pertinente para integrar tanto las condiciones naturales como los sistemas establecidos por las sociedades locales" (Bouquet, 2012 , p.65). La GIRH retoma este concepto y lo presenta como un recurso global que integra el suelo, la vegetación y el agua (Descroix, 2012, p.77).

S. Ghiotti identificó un proceso de internacionalización de la gestión del agua en torno al enfoque de las cuencas internacionales transfronterizas a partir de la década de 1990. Este proceso fue motivado por científicos, técnicos y gestores, los cuales se encargaron de difundir los principios de la GIRH a través de su producción 
académica y proyectos científicos ${ }^{8}$. En esta internacionalización de la GIRH, las organizaciones internacionales y los donantes desempeñaron un papel muy importante. La participación del Banco Mundial (1997) (Molle, 2012b, p.27), fue decisiva para mantener el tema del agua y de las cuencas en la agenda internacional (Ghiotti, 2014, p.21).

Figura 1. Los "tres pilares" de la GIRH según Molle

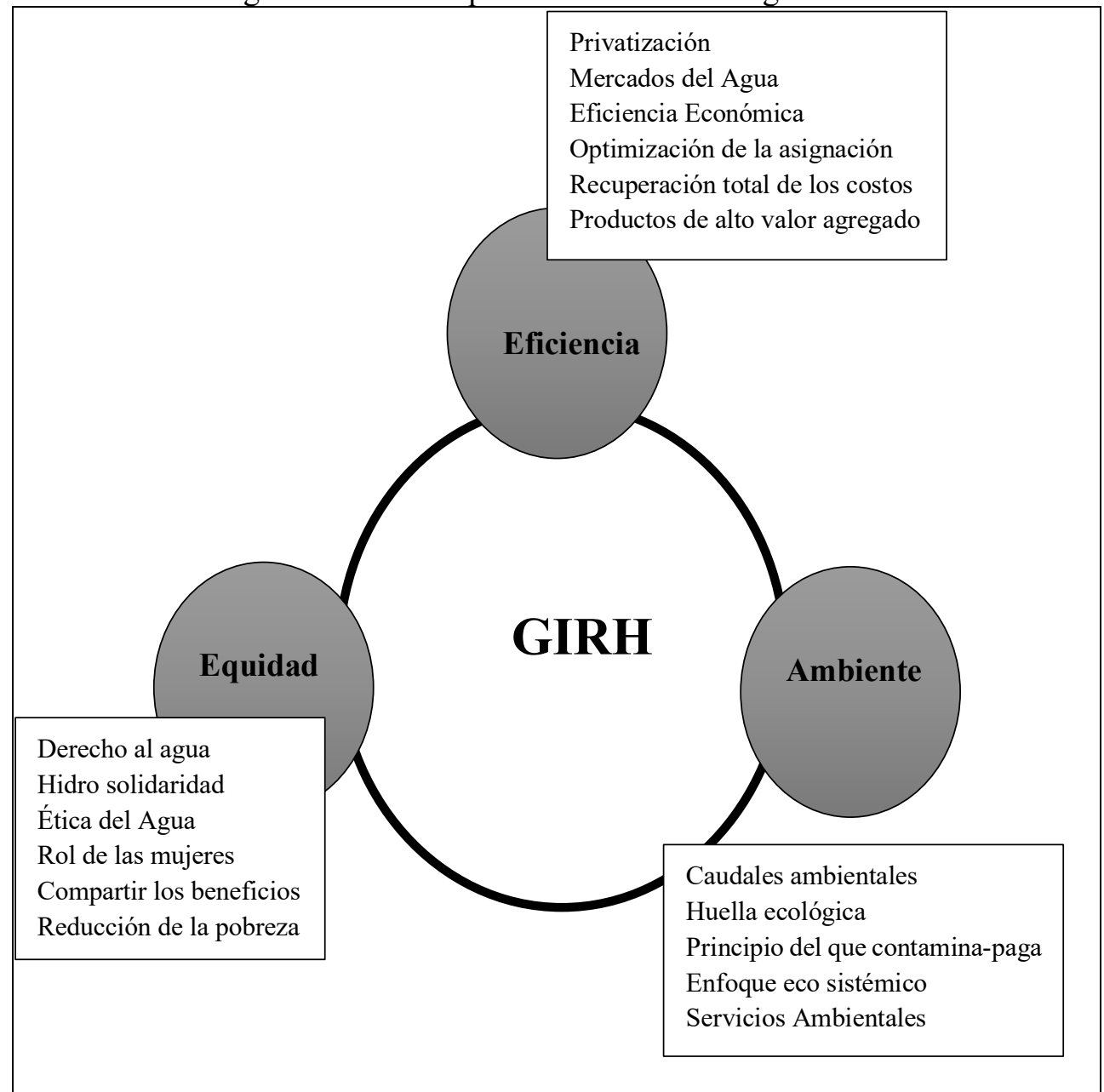

Fuente: Figura 1.1. en Molle (2012b).

En 1993, el Banco Mundial, con el Documento de Política General sobre el Agua, definió orientaciones en materia de agua y cuencas. Este documento establece que los Estados en vías de desarrollo que deseen acceder a préstamos para desarrollar proyectos hídricos deben adoptar este paradigma (GIRH) y seguir una "buena legislación sobre el agua" (Trottier, 2012, p.191). La ayuda internacional (préstamos,

Es así como el tema del agua se convirtió en una prioridad durante la Conferencia Internacional de París sobre el Agua y el Desarrollo Sostenible (1998) y en el Segundo Foro Mundial del Agua de La Haya (2000). 
donaciones, proyectos de cooperación, etc.) para los Estados del Sur fue condicionada a la aceptación de la GIRH y a la gestión territorial por cuencas hidrográficas, así como a la implementación de las políticas económicas neoliberales (Programas de Ajuste Estructural) (Descroix, 2012, p.98).

De esta forma, el concepto de GIRH se incorporó gradualmente a las legislaciones nacionales relacionadas con la gestión del agua en todo el mundo. Sin embargo, algunos autores afirman que esta incorporación se ha logrado de manera superficial. Paulatinamente, otros organismos intergubernamentales (OIG) como el BID empezaron también a apropiarse de la retórica de la GIRH y a internacionalizarla.

La difusión mundial de la GIRH fue promovida por la Global Water Partnership (GWP), institución fundada en 1996 por el Banco Mundial (BM), el Programa de las Naciones Unidas para el Desarrollo (PNUD), el Organismo Sueco de Desarrollo Internacional (SIDA) y el Consejo Mundial del Agua. Inicialmente GWP se pensó como un think tank, es decir un grupo de reflexión internacional para abordar los problemas del agua y promover la GIRH en el mundo. Sin embargo, actualmente, funciona como una red que reúne a una multiplicidad de organizaciones no gubernamentales (ONG), universidades, organismos de las Naciones Unidas, instituciones financieras, empresas y organismos de cuenca (Trottier, 2012, p.180). Esta organización ha incidido en las legislaciones y ha producido una gran cantidad de documentos y de cajas de herramientas (tool kits) los cuales son utilizados por tomadores de decisión en materia de agua. La GWP está presente en la región centroamericana y cuenta con antenas en cada uno de los países del Istmo. Para el caso de Costa Rica, la oficina de la GWP está alojada en la actualidad en la Universidad de Costa Rica en su Unidad de Gestión Ambiental.

Por otro lado, en mayo de 1997, la Asamblea General de las Naciones Unidas adoptó la Convención de las Naciones Unidas sobre el Derecho de los usos de los cursos de agua internacionales para fines distintos de la navegación que aportó un nuevo marco jurídico no vinculante para los Estados. Esta convención fue también fundamental en el proceso de internacionalización de la GIRH (Ghiotti, 2014, p.21).

Junto con las organizaciones intergubernamentales (OIG) y los bancos de desarrollo, las organizaciones ambientales internacionales y las ONG han utilizado la GIRH para promover la conservación de la naturaleza. En sus planes de acción, estas organizaciones han articulado el enfoque eco sistémico y la GIRH. La UICN es quizás el mejor ejemplo (Molle, 2012b, p.35). Esta organización es una de las más asiduas defensoras del enfoque por ecosistemas, así como de la GIRH y del enfoque por cuencas. El Programa Mundial del Agua de la UICN es el marco institucional que engloba tres de los proyectos estudiados que fueron aplicados en Centroamérica: la Iniciativa Agua y Naturaleza (WANI), el Proyecto BRIDGE y el Proyecto de Buena Gestión del Agua para la Adaptación al Cambio Climático (UICN, 2012b). Este Programa ha contribuido en gran medida a la difusión de la GIRH en todo el mundo gracias a su estructura descentralizada (oficinas regionales en todo el mundo) y a sus numerosas alianzas multi-escalares. Cabe señalar que los donantes han recurrido gradualmente a estas organizaciones y $\mathrm{ONG}$ para que sean estas las operadores de estas acciones (Bouquet, 2012, p.68), sin pasar por las instituciones de los Estados en los que se ejecutan sus proyectos e intervenciones. Estos proyectos promovían la GIRH y la gobernanza en las cuencas transfronterizas del río Sixaola compartido por Costa Rica y Panamá, la cuenca del Coatán entre México y Guatemala y la del Goascorán entre Honduras y el Salvador. 
Estas iniciativas, declaraciones y convenciones introducen un nuevo paradigma que articula tres elementos: los cursos de agua, la gobernanza supraestatal y sus múltiples usos (Ghiotti, 2007, p.22). Lo que pone en evidencia que alrededor de las cuencas hidrográficas, los usos se han diversificado, así como los actores ya sean estos usuarios o administradores. En definitiva, el Estado ya no tiene el monopolio de la GIRH y comparte esta tarea con una amplia gama de actores con intereses muy diversos.

\section{Legislación e la institucionalidad del Agua en Costa Rica}

En Centroamérica, la GIRH fue introducida y promovida por toda una institucionalidad regional como del Sistema de Integración Centroamericano (SICA), la Comisión Centroamericana de Ambiente y Desarrollo (CCAD) y el Comité Regional de Recursos Hidráulicos (CRRH). Además se desarrolló a finales de los años 2000 una Estrategia Centroamericana para la Gestión del Recurso Hídrico (ECAGIRH) (Grupo Interagencial del Agua, 2009) que incluye los principios de la GIRH y promueve la gestión por cuenca. Sin embargo, el proceso de incorporación de estos principios y conceptos en las legislaciones nacionales no ha sido exitoso ya que tres de los siete países de la región, no cuentan con leyes de aguas (Belice, El Salvador y Guatemala) y los que las poseen como Honduras (1927), Costa Rica (1942) y Panamá (1966), estas son consideradas antiguas, obsoletas y poco restrictivas. Sólo Nicaragua cuenta con una ley actualizada, denominada Ley General de Aguas Nacionales del 2007, sin embargo, su aplicación ha sido muy cuestionada. En este sentido, Rocio Córdoba consultora internacional y ex coordinadora de la Unidad de Gestión del Agua de la UICN (Comunicación personal, 16 de julio 2020), afirma que países como Honduras, Nicaragua y Panamá si bien cuentan con una legislación en materia de aguas, no cuentan con la capacidad técnica e institucional para implementarla. En el caso costarricense, la ley de Aguas que data de 1942 fue "pensada para un país campesino" según José Miguel Zeledón director de la Dirección de Aguas (Comunicación personal, 21 de agosto 2020). Por su parte, Esteban Monge, Coordinador del Programa de Recurso Hídrico del Centro de Derecho Ambiental y de Recursos Naturales (CEDARENA) (Comunicación personal, 6 de agosto 2020), considera a esta ley "obsoleta" debido a que está "enfocada en aprovechamiento no en el uso sostenible del recurso". Yamileth Astorga, ex directora del Instituto Costarricense de Acueductos y Alcantarillados (AYA) (Comunicación personal, 7 de octubre 2021), señala que, si bien la ley de Aguas fue "visionaria" en la década de los años 1940, para la compleja realidad actual del sector hídrico, ésta cuenta con importantes vacíos ya que no hay sanciones para los que contaminan ni incentivos para promover su el razonable del agua.

Otra característica del sector hídrico en Costa Rica es su división, ya que en la actualidad la gestión del agua es realizada de forma desagregada por tres instituciones:

1. La Dirección de Aguas del MINAE, la cual, si bien es el ente rector, su competencia se reduce a las aguas superficiales. 
2. El Servicio Nacional de Aguas Subterráneas, Riego y Avenamiento (SENARA) el cual como su nombre lo indica gestiona las aguas subterráneas para proyectos de riego.

3. El Instituto Costarricense de Acueductos y Alcantarillados (AYA) el cual se encarga del abastecimiento y el saneamiento.

Para Yamileth Astorga (Comunicación personal, 7 de octubre 2021), frente a este escenario, afirma que "es imposible gestionar las aguas superficiales sin tomar en cuenta las aguas subterráneas", por lo que, para ella, uno de los grandes problemas del país es la atomización a nivel institucional y la falta de una verdadera gestión integrada.

Además, existe una falta de claridad en cuanto a las competencias institucionales ya que en Costa Rica existen alrededor de 100 cuerpos normativos distintos que buscan regular el agua, lo que ha generado una importante dispersión y dificulta la gestión coordinada de este recurso (Rodríguez Echavarría, 2018).

Más recientemente, el 5 de junio del 2020, en el marco del día del Ambiente, el presidente de Costa Rica, Carlos Alvarado firmó la ley n. 9849 a través de la cual se reformaba el artículo n.50 de la Constitución Política, declarando al Agua como un derecho humano. La ley define también al agua como un bien de la Nación cuyo "acceso es un derecho básico, irrenunciable y esencial para la vida" (Ugarte Jiménez, 2020). Esta reforma, es considerada tanto por Esteban Monge de CEDARENA (Comunicación personal, 6 de agosto 2020) como por Eva Carazo de la Alianza Nacional por la Defensa del Agua (Comunicación personal, 1 de junio 2021) un gran logro para el movimiento ambiental, sin embargo, ambos señalan que ahora el reto es garantizar la eficacia jurídica y operativizar esta reforma en planes y políticas.

\section{3. ¿La GIRH, una respuesta occidental y un discurso hegemónico?}

A escala mundial, el discurso de la GIRH se ha convertido gradualmente en un "discurso hegemónico" casi irrefutable (Trottier, 2012, p.19) que introduce a la cuenca hidrográfica como la unidad ideal para la gestión del agua y del territorio (Hernández-Ulate, López-Ramírez y Jimenez-Elizondo, 2009, p.16). De hecho, en las iniciativas implementadas por organizaciones como el BID o la UICN, existe una aceptación casi generalizada de la aplicabilidad de la GIRH y de como el territorio debe de ser gestionado por cuencas (Rodríguez, 2014, p.403). Su pertinencia no es puesta en duda y los únicos debates son los relacionados con su aplicación.

Entrevistas realizadas a técnicos, expertos del agua y académicos en Costa Rica, dejan claro la apropiación tanto de la GIRH como de la gestión por cuenca. Por ejemplo, Cynthia Hernández (Comunicación personal, 4 de agosto 2020) punto focal de GWP en la Unidad de Gestión Ambiental de la Universidad de Costa Rica, está convencida de la importancia de gestionar el agua alrededor de la cuenca, para ella la gestión por cuenca es un modelo de gestión ideal que permite "promover el desarrollo y los recursos que se encuentran en la cuenca, considerando todos los factores (social, económico y ambiental)" y "considerando a diferentes actores, sectores y disciplinas", es decir con "un trabajo coordinado y con una organización de base fuerte". En este sentido, Julio Montes de Oca ex coordinador del proyecto BRIDGE de la UICN (Comunicación personal, 12 de junio 2020), afirma que la gestión por 
cuenca aporta "una unidad geográfica que facilita el trabajo". Para él, la GIRH y la gestión por cuenca aportan "una metodología o un método de abordaje del paisaje que permite relacionar actores y temas de manera flexible en donde la cuenca es definida como un paisaje interconectado por el agua".

En palabras de Esteban Monge de CEDARENA (Comunicación personal, 6 de agosto 2020) la GIRH es útil, porque es un modelo "de manejo y relación con el agua como elemento vital que trata de ver todas las variables que impactan en esa relación con una visión pragmática de como promover la gobernanza de un recurso finito, frágil e indispensable para la vida. La GIRH reconoce la complejidad de esa relación ser humano-agua".

Por otro lado, académicos como Christian Birkel director del Observatorio del Agua y Cambio Global de la UCR (Comunicación personal, 19 de junio 2020), ve la GIRH como "un concepto ideal, como una utopía, utilizando la cuenca como unidad natural de análisis". Para él la gestión por cuenca puede ser definida como "una herramienta que debe ser útil para lograr una planificación razonable de los retos relacionados al agua (agua potable, agrícola, energética)". Además, él ha sido el ideólogo de la Maestría en Gestión Integrada del Recurso Hídrico que se imparte en la Universidad de Costa Rica.

Es así cómo, a través de las entrevistas, se pudo identificar una adhesión casi generalizada por parte de cooperantes, académicos y de los mismos activistas ambientales a la GIRH, a la gestión por cuenca y a los principios de Dublín. Los cuales las perciben como la solución a los principales problemas que enfrenta el agua en Costa Rica como la dispersión normativa, la falta de una legislación actualizada que garantice la participación y establezca sanciones a las personas que contaminan el agua. Desde estas organizaciones, los conceptos de GIRH y gestión por cuenca se presentan generales y flexibles según los objetivos de los mismos proyectos. Todas las personas entrevistadas exaltan el modelo de gobernanza propuesto por la GIRH centrado en la participación de los diversos usuarios presentes en las cuencas. Sin embargo, pocos cuestionan su representatividad y efectividad.

Es por esto, que en años 2000 una gran diversidad de actores de la sociedad civil (académicos, activistas ambientales y algunos funcionarios públicos) en Costa Rica promovieron un proyecto de ley por iniciativa popular para incorporar los principios de la GIRH en Costa Rica. Este proyecto tenía por objetivo ordenar la institucionalidad que gestionaba el agua por considerarla dispersa, garantizar la participación de todos los diferentes usuarios del agua a través de comités de cuencas, así como promover medidas más restrictivas en cuanto al uso y aprovechamiento del recurso. Para presentarlo en el 2009 se requirió un importante trabajo de consulta y recoger alrededor de 160000 firmas (requisito para presentar un proyecto por iniciativa popular). Este proyecto fue debatido en Asamblea Legislativa, sin llegar a un segundo debate, debido a que después de una consulta de constitucionalidad, la Sala Constitucional, identificó elementos no compatibles con la Constitución, especialmente las reformas que habían introducido el sector agroindustrial, después de haber realizado mucha presión e incidencia.

Posteriormente, en el 2020 desde el Ministerio de Ambiente y Energía se presentó a valoración de la Asamblea Legislativa el Proyecto de Ley para la Gestión Integrada del Recurso Hídrico, $\mathrm{N}^{\circ}$ 20212. Este proyecto fue el resultado de un largo proceso de negociación y lobby político que implicó una serie de concesiones, como 
renunciar a la incorporación de mecanismos de participación ciudadana como los consejos de cuenca y a la incorporación de sanciones administrativas.

Es interesante notar que, a pesar de las concesiones pactadas, ambos proyectos generaron la resistencia de las cámaras agropecuarias las cuales según Esteban Monge de CEDARENA (Comunicación personal, 6 de agosto 2020) vieron en "la participación una amenaza y en el derecho ambiental una traba (...) en especialmente el principio de quién contamina paga".

Es así como la GIRH emerge como la solución indiscutible (Julien, 2012; Trottier, 2012) para una gran diversidad de actores y al mismo tiempo como una amenaza para los sectores agrícolas.

Sin embargo a escala internacional, sigue siendo una solución que la comunidad epistémica del agua ha ideado y aceptado unánimemente como la estrategia para hacerle frente a la crisis del agua (Julien, 2012, p.8). Como sostiene F. Julien, "la GIRH ha alcanzado el estatus de discurso hegemónico, es decir, que sus principios constitutivos forman ahora una especie de sentido común o una evidencia, sin ofrecer otras alternativas para la comunidad epistémica del agua" (2012, p.7). La preponderancia de los grupos de expertos del norte y de las organizaciones intergubernamentales en los procesos de elaboración de este discurso también evidencia el "dominio occidental en la comunidad epistémica del agua" (2012, p.8).

Las manifestaciones de poder en el sector del agua son caracterizadas M. Zeitoum y J. Warmer como "hidro-hegemonía", noción con la que describen no sólo las relaciones de poder que se establecen entre las comunidades epistémicas occidentales del agua y las sociedades del Sur en el momento en que estas comunidades transfieren la noción de GIRH y de cuenca, sino también las relaciones de poder que se establecen en una cuenca entre un Estado situado aguas arriba y el Estado situado aguas abajo (Zeitoum y Warner, 2006, p.438).

La difusión de este discurso en Centroamérica ha estado a cargo de las ONG, las OIG y las organizaciones internacionales como la UICN, GWP o la Banca de Desarrollo (BM y BID) han sido los principales responsables de la difusión de la fórmula de la GIRH. Estas organizaciones han llevado a cabo diferentes actividades destinadas a motivar una opinión favorable sobre la GIRH. Es así como, por ejemplo, en Costa Rica, el Fondo de Incidencia de la UICN, fue el responsable de financiar tanto el proceso de consulta (talleres regionales) como la recolección de firmas para la presentación del proyecto de ley por iniciativa popular. Sin esta intervención no se hubiera contado con los recursos necesarios para garantizar la participación y la elaboración colaborativa de este proyecto de ley.

El papel de las organizaciones internacionales ha sido crucial en la aplicación de la GIRH a nivel mundial, cabe señalar que las medidas de GIRH hoy en día dependen en su mayor parte del financiamiento internacional (Ghiotti, 2014, p.22). En Centroamérica, el SICA, la Organización de Estados Americanos (OEA) y la UICN han realizado muchas investigaciones sobre el estado de los recursos hídricos, especialmente sobre el estado de las aguas subterráneas y las cuencas transfronterizas. Además, han participado en la elaboración de la Estrategia Centroamericana para la Gestión de los Recursos Hídricos (ECAGIRH) cuyo plan de acción aún no ha sido reconocido por los Estados centroamericanos. De esta forma, la comunidad epistémica del agua de los países del Norte influyó profundamente en los debates regionales, especialmente a través de la participación protagónica de la OEA. 
En Costa Rica, los proyectos de cooperación estudiados ${ }^{9}$ emprendieron actividades de promoción y talleres de capacitación a diferentes escalas (regional, nacional y local) para presentar estos conceptos a los tomadores de decisión, al sector académico, a las organizaciones de base y a las ONG locales. Para esto, organizaciones como la UICN, han elaborado numerosos materiales de difusión y sensibilización, como folletos, vídeos, anuncios en radios comunitarias y toolkits. Los toolkits son documentos en los que se explican las metodologías utilizadas, los conceptos y las "buenas prácticas". Ejemplos de estos kits de herramientas son las ocho guías desarrolladas por la Iniciativa del Agua y Naturaleza de la UICN. Cada una de estas guías distribuidas por las Oficinas de las antenas regionales de la UICN alrededor del mundo, aborda un elemento clave de la GIRH ${ }^{10}$. En los documentos institucionales que se distribuyen durante los talleres y reuniones, la UICN declara su adhesión a la gestión por cuenca, a la GIRH y su compromiso de difundirla en todo el mundo: "La gestión integrada de los recursos hídricos (GIRH) es una técnica practica y aplicable. La UICN promueve un enfoque por ecosistemas donde la planificación de la GIRH se complementa con acciones piloto que muestran resultados y dan respuesta a las prioridades locales" (UICN, 2012c) ${ }^{11}$.

Además, promueve el establecimiento de instrumentos jurídicos y de gobernanza como la creación de mecanismos normativos (códigos de conducta) y deliberativos (comités de cuenca, y plataformas de multi-actores) para mejorar la gestión del agua. La cuestión de la gobernanza es, pues, un tema omnipresente, ya que no sólo todos los proyectos estudiados se refieren a la gobernanza, sino también porque se presenta como uno de los elementos indispensables de la GIRH. Además, su uso es reiterativo; sólo en el folleto del proyecto BRIDGE ${ }^{12}$ de la UICN (UICN, 2012d), que es un documento de dos páginas, la palabra gobernanza se utiliza doce veces. El objetivo de este proyecto es "es mejorar la cooperación entre los Estados ribereños mediante el uso de la hidrodiplomacia e incrementar los beneficios socioeconómicos, ambientales y políticos que derivan del agua" (UICN, 2012d).

A escala mundial, la UICN ha promovido y financiado experiencias de gestión por cuencas que se han convertido en hitos, como el Proyecto para mejorar la gestión del agua del río Volta (PAGEV) en África, el cual siempre es mencionado como una buena práctica por sus logros en cuanto a marcos regulatorios compartidos. Es así como la experiencia del río Volta ha servido de modelo para otros proyectos que se han aplicado en otros países y otras regiones del mundo. Además, este proyecto promovió el establecimiento de la Autoridad de la Cuenca del Volta (VBA) lo cual se ha tratado de replicar en otras cuencas transfronterizas centroamericanas como el caso de la cuenca del Sixaola (entre Costa Rica y Panamá) o en el Trifinio

9 Los proyectos estudiados fueron los proyectos Alianzas Bridge de la UICN y los proyectos del BID, "Proyecto gestión integrada de la cuenca del río Sixaola (financiado por el BID y el GEF) y "Proyecto para el Desarrollo Sostenible de la Cuenca del río Sixaola promovido por el BID en colaboración de Ministerio de Agricultura y Ganadería de Costa Rica.

10 Siete guías desarrolladas por la UICN para difundir la GIRH: 1. Cambio: Adaptación de la Gestión de los Recursos Hídricos al Cambio Climático. 2. Caudal: La mayor parte del agua fluye. 3. Negociar: Llegar a acuerdos sobre el agua. 4. Pagar: establecer pagos por los servicios de las cuencas hidrográficas. 5. Normar: Reformar la gobernanza del agua. 6. Compartir: Gestión del agua a través de las fronteras. 7. Valor: Contar los ecosistemas como la infraestructura del agua. Ver http://www.waterandnature.org/en/resources/toolkits

11 Brochure du Programme Mondial de l'Eau de l'UICN: https://www.iucn.org/downloads/water_brochure_spanish_1.pdf

12 Ver https://www.iucn.org/sites/dev/files/content/documents/bridge_pdf_spanish_2015.pdf 
(compartida entre Honduras, El Salvador y Guatemala). Si comparamos estas iniciativas llevadas a cabo en África con experiencias como la del río Sixaola, en cuanto a objetivos y modelos de aplicación, la similitud es sorprendente.

Es así, como la transferencia de este discurso hegemónico se lleva a cabo a través de diferentes métodos: presión, lobby, proyectos de cooperación, préstamos, fondos que financian proyectos o iniciativas de incidencia, entre otros. Para M. Zeitoum y J. Warner, la efectividad de los métodos del actor hegemónico depende de su capacidad de persuadir a los actores subordinados y hacer que no sólo acepten su autoridad, sino que también adopten e interioricen los valores y normas que tienen por objeto imponer una solución entre otras (en este caso la GIRH) (Zeitoum y Warner, 2006, p.438).

De esta forma la GIRH se ha constituido como un paradigma occidental dominante que se ha exportado de norte a sur (Ghiotti, 2006, 2007; Julien, 2012). Algunos autores asemejan la GIRH a una nueva forma de colonialismo moderno (Trottier, 2012, p.191) "con sabor neoliberal" (Julien, 2012, p.10). Si embargo, si bien estas comunidades epistémicas del Norte han logrado transferir el discurso de la GIRH a muchos actores en Centroamérica, esta apropiación no se ha traducido en marcos regulatorios o en políticas concretas. Además, existen importantes sectores como el agroexportador que perciben la GIRH como una amenaza para sus operaciones.

\section{La cuenca hidrográfica, la voluntad de inventar un territorio}

\subsection{La gestión por cuenca, una construcción social y política}

Como ya se ha mencionado, la GIRH propone la cuenca hidrográfica como escala de gestión territorial. Para L. Descroix, la cuenca es una unidad hidrográfica coherente que integra todos los elementos del ciclo del agua (suelo, cobertura vegetal, régimen hídrico, entre otros) (Descroix, 2012, p.78), así como las actividades humanas. Este modelo de gestión por cuencas se ha promovido a nivel internacional "para superar los conflictos entre los usos y los usuarios de los recursos hídricos" (Ghiotti, 2014). J. Trottier recuerda que la GIRH y el modelo de cuencas hidrográficas presuponen un "orden natural objetivado", que encuentra su base en la ciencia (hidrología), alrededor del cual se debería de crear toda una ingeniería social" (Trottier, 2012, p.183), con el fin de dejar de lado el carácter diverso y cambiante de este orden social. Es así como cuenca hidrográfica proporciona una respuesta "natural" que conlleva cierta neutralidad.

No obstante, si bien la gestión de las cuencas tiene, según los científicos y técnicos, "cualidades innegables", se ha desarrollado todo un debate en torno a ella desde el punto de vista ideológico. Algunos autores denuncian la "dictadura de la GIRH" y la "obligación de la cuenca hidrográfica" y consideran que estos dos modelos sólo deben presentarse como un modelo que existe entre otros. L. Descroix sostiene que la gestión por cuencas es sólo una de las escalas de gestión posibles (Descroix, 2012, p.98) y debe de presentarse sólo como un conjunto de recomendaciones adaptables a cada país, siempre y cuando se "respete la diversidad cultural y natural de cada sociedad", diversidad que, según este autor, puede conducir a mejorar sustancialmente la gestión del agua para las futuras generaciones (2012, p.97). 
La decisión de elegir a la cuenca hidrográfica como unidad de gestión ideal es, de hecho, una elección política. Sin embargo, desde la comunidad epistémica del agua se ha tratado de despolitizar esta elección al presentarla como realidad "intangible e inevitable, porque es natural" (Descroix, 2012, p.98) y, por lo tanto, incuestionable. Sin embargo es preciso aclarar que la gestión por cuenca es "una construcción social y política resultante de la confrontación de intereses y de la relación de poder que existe entre múltiples actores" (Ghiotti, 2014, p.23).

\subsection{Las cuencas hidrográficas frente a la coexistencia de "otros" territorios}

El modelo de gestión por cuencas hidrográficas es, pues, una construcción social y política que tiene por objeto crear un territorio, es decir, un perímetro delimitado según criterios hidrológicos (orden natural), pero que, al mismo tiempo, genere sentido de pertenencia (orden social) para los Estados, las autoridades locales y los actores locales. Es decir, una unidad espacial que sea reconocida y apropiada por una gran diversidad de actores, que aceptan gestionar el agua, la naturaleza y las actividades sociales y productivas alrededor de la cuenca. Esta voluntad de crear un territorio alrededor de la cuenca implica principalmente el paso de territorios con una matriz pensada desde el Estado y su administración hacia "territorios hidrológicos" (Ghiotti, 2014, p.22).

La cuenca hidrográfica se presenta como una realidad "técnica e hidráulica", así como por su aparente neutralidad que parece desprenderse de las divisiones políticoadministrativas (2014, p.18), es decir, de los municipios, de los cantones y de las provincias. Sin embargo, paralelamente a las divisiones políticas establecidas por los Estados, también existen otras expresiones territoriales en Centroamérica como lo son los territorios indígenas. El modelo de gestión por cuenca se enfrenta así a una dificultad: ¿cómo coexistir con estas divisiones preexistentes que imponen discontinuidades que no corresponden con los límites establecidos por la cuenca?

Las entrevistas realizadas con los actores locales (gobiernos locales, autoridades indígenas Bribri y representantes de las cooperativas productoras de plátano y cacao en la cuenca del Sixaola) $)^{13}$, permitieron observar que, si bien estos actores participan en las actividades de promoción de GIRH convocadas por organizaciones internacionales como la UICN, no existe una verdadera apropiación del concepto de cuenca, es más muchos se refieren a la comisión Binacional de Cuenca del Sixaola como la "Comisión de la UICN".

En efecto, estos actores locales siguen pensando en el territorio según los límites nacionales y administrativos, o los límites de sus fincas y territorios indígenas. A este respecto, A. Brum afirma:

La cuenca hidrográfica constituye ciertamente un marco operativo para instituciones técnicas y financieras específicas (...), pero cabe preguntarse si la organización tan compleja que se establece, no contribuirá más bien a evitar que los grupos

13 Entrevistas realizadas a representantes a la Junta de la Asociación de Desarrollo Territorial del territorio BriBri el 15 de septiembre de 2012 en Suretka y a productores de plátano de la ASOPLATUPA el 10 de julio de 2012 en Paraíso, Talamanca (Costa Rica). Además, entrevistas realizadas a mujeres productoras de cacao de la ACOMUITA en julio 2016. 
sociales susceptibles se apropien de este espacio para convertirlo en su territorio (Brun y Lasserre, 2006, p.9).

En lo que respecta a los territorios indígenas, cabe recordar que existen disposiciones especiales nacionales e internacionales para determinar los limites de sus territorios y que estos fueron reconocidos muy tarde por los Estados, en un contexto particular que corresponde a un período de "resurgimiento de la problemática indígena" en todo el continente americano (Bengoa, 2007, p.78). C. Gros se refiere a la existencia, durante la década de los años 1990 de un proceso de "reindigenización o etnogénesis" (Gros, 1998, p.1990). Este proceso de "reindigenización" es el resultado de una valorización internacional de las poblaciones indígenas que condujo a la generación de políticas de "acción afirmativa" que posteriormente incitaron la elaboración de legislaciones nacionales e internacionales para proteger los derechos de las poblaciones indígenas (Bengoa, 2007, p.79). Es en este contexto, que muchas de las constituciones nacionales en Centroamérica han reconocido y formalizado los territorios indígenas.

Estos territorios se rigen por dos principios fundamentales: la autonomía y el autogobierno (Bengoa, 2007, p.76). La auto-organización o el autogobierno implica que estas poblaciones indígenas dentro de sus territorios pueden elegir las formas de gobierno que les convengan. Por lo general, estas formas combinan las formas tradicionales de gobierno con las formas modernas de gobierno (Bengoa, 2007, p.76), como las "asambleas indígenas" o las "asociaciones de desarrollo indígena", que funcionan como autoridades de estos territorios. Además, en relación con la propiedad de la tierra, estos territorios, establecen sistemas de propiedad colectiva con lógicas muy diferentes al binomio público-privado occidental (Trottier, 2012, p.188). Al reconocer la GIRH el valor económico del agua, han surgido importantes debates relacionados con la privatización del recurso y del servicio, lo que se aleja diametralmente de la noción de territorio comunitario, que es uno de los principios fundadores de estos territorios indígenas.

Conviene precisar, que los territorios indígenas, al menos en Centroamérica coinciden con áreas protegidas o con fincas que dan servicios agroecológicos (reforestación de especies endémicas, producción sin agroquímicos, etc.). Por lo tanto, se trata de un sistema de gestión del agua que no se basa en la GIRH y que se despliega en un área mucho más pequeña que la de una cuenca hidrográfica. Esto nos lleva a referirnos a las teorías relacionadas con el gobierno de los bienes comunes propuestas por Elinor Ostrom, la cual tras examinar numerosas experiencias de autogestión, llega a la conclusión de que, en el plano más local, la gestión participativa por parte de los usuarios directos de los recursos puede ser eficaz (Ostrom, 2010). El enfoque de Ostrom nos invita a interesarnos en la capacidad de las comunidades más locales "para resolver problemas de acción colectiva, mediante la construcción de sistemas de reglas relativamente autónomos, 'modos de gobierno' adaptados a los problemas específicos a los que se enfrentan” (Weinstein, 2013).

Lo que nos parece interesante de este enfoque para comprender el caso de estos territorios indígenas es que este enfoque sostiene que estos sistemas se gestionan generalmente por normas que "no son necesariamente normas de mercado o estatales", sino tradiciones y se organizan mediante procesos de autogobierno emprendidos por las comunidades locales dentro de perímetros muy restringidos (Ostrom, 2010; Weinstein, 2013). Sin embargo, a pesar del reconocimiento científico de estos 
sistemas comunitarios, las legislaciones sobre el agua que hacen referencia a la GIRH han tendido a ignorar la existencia de estos regímenes de propiedad comunitaria que ya habían emprendido acciones para la protección del agua (Trottier, 2012, p.188).

A esto se suma el hecho de la GIRH alienta la participación de los actores privados en plataformas multi-actores (comités o comisiones de cuenca) para toda la cuenca, lo que implica que tanto los actores locales como las poblaciones indígenas deben ceder parte de su autonomía en favor de la "gobernanza" de toda la cuenca. Esto puede representar un riesgo para los territorios indígenas puesto que, a pesar de estar protegidos por la legislación nacional, estas comunidades pueden verse amenazadas por los intereses de empresas privadas extractivas (monocultivos, mineras, petroleras, entre otras) que tratan de encontrar nuevos territorios de explotación. Es así como la forma en que se incluye a los pueblos indígenas a participar en las estructuras de gobernanza de las cuencas (comités de cuenca), del agua, no suele corresponder con su percepción de la naturaleza y de la propiedad ya que muchas veces deben de hacerlo de acuerdo con las normas y la lógica impuestas por las organizaciones internacionales (Trottier, 2012, p.188).

De esta forma, nos enfrentamos a dos lenguajes de valoración dicotómicos que se enfrentan en los procesos de gobernanza, es decir a dos formas diversas y a veces antagónicas de darle un significado a la naturaleza (Martínez Alier, 2005). Por un lado, uno que se basa en la naturaleza como un bien común y otro que la percibe como recurso, como un bien de mercado. Comunidades indígenas centroamericanas llegan a referirse al río como un actor en sí mismo, recordemos a Berta Cáceres del Consejo Cívico de Organizaciones Populares e Indígenas de Honduras (COPINH) en su lucha contra la represa Aguas Arcas cuando decía: "Yo sabía lo duro que iba a ser. Pero también sabía que íbamos a triunfar. Me lo dijo el río".

J. Trottier, concluye que gestionar desde el perímetro de la cuenca no es algo inevitable, "natural, científico o neutral", es una decisión política. Para ella:

La escogencia de la cuenca como unidad natural de gestión del agua la hacen las ciencias naturales, pero no de acuerdo con el orden natural que producen. Esta elección la hacen las ciencias naturales de acuerdo con el orden social deseado por las ciencias naturales para gestionar el agua. Corresponde así a la estructura de poder que los científicos naturales consideran como legítima (2012, p.187).

A parte de los territorios indígenas, en la región existen también otros territorios que por sus lógicas de uso del recurso hídrico ven en la GIRH y en la gestión por cuenca una amenaza. Este es el caso de los territorios extractivos. Por actividades extractivas entenderemos actividades productivas que remueven de forma intensiva y se apropian de recursos provenientes de la naturaleza ya sean minerales, hidrocarburos (petróleo y gas natural) monocultivos (piña, palma, banano, entre otros), material forestal entre otros (Acosta, 2011; Gudynas, 2009, 2013). Estos territorios controlados muchas veces tanto por empresas nacionales como transnacionales, han generado procesos de apropiación de la naturaleza y formas de organización territorial que muchas veces se asemejan a los antiguos enclaves bananeros (Rodríguez Echavarría, Obando y Acuña, 2018).

En Costa Rica los sectores agropecuarios han sido los principales detractores de todas las iniciativas de leyes de agua, especialmente las cámaras de empresas ligadas 
a los monocultivos de caña, azúcar y piña. Por ejemplo, con solo $51.100 \mathrm{~km}^{2}$, Costa Rica según, el Programa de Monitoreo de Cambio de Uso de Paisajes Productivos (MOCUPP) del Programa de las Naciones Unidas para el Desarrollo (PNUD) destinó 65.442,41 ha en el año 2019 para cultivo de piña siendo hoy en día, el primer exportador de piña del mundo. Desde la década de los años ochenta este cultivo ha crecido sin un verdadero control estatal, haciendo un uso indiscriminado de agroquímicos y pesticidas muy contaminantes para los acuíferos y las aguas superficiales (Rodríguez-Echavarría y Prunier, 2020).

Yamileth Astorga, ex directora del AYA (Comunicación personal, 7 de octubre 2020) afirmaba durante su entrevista: "aquí los agricultores hacen y deshacen lo que quieren con el agua, desvían ríos, talan árboles en las zonas protegidas (...), contaminan las aguas (...) porque no es un delito contaminar las fuentes de agua".

Estos sectores, rechazan la GIRH y la gestión por cuencas por un lado porque genera mecanismos de participación que implicarían incorporar a los demás usuarios en la gestión de una cuenca y por otro lado rechazan el principio de dotar de valor económico al agua porque no quieren hacerse responsables de la contaminación que han generado. Para Patricia Madrigal, ex Viceministra de Ambiente (Comunicación personal, 19 de octubre 2020), también se oponen a la gestión integrada del agua porque los marcos regulatorios propuestos establecen áreas de protección que disminuyen el área productiva de los territorios.

Es así como la incidencia política generada por estos sectores agropecuarios ha dificultado la aprobación de las diferentes iniciativas de ley. Esto es paradójico, ya que si analizamos los contenidos de la GIRH se puede concluir que esta promueve una gobernanza ambiental neoliberal que no busca poner en riesgo los intereses de los sectores productivos. Sin embargo, en Costa Rica es percibida como una amenaza.

La GIRH ha fallado como estrategia de neoliberalización del agua, no por la resistencia de los sectores sociales y académicos, sino por la resistencia de las élites políticas y económicas que han desarrollo un capitalismo maduro más profundo y arraigado que no necesita encubrirse ni con discursos ni estrategias. Con esta negativa buscan sostener las lógicas de despojo y de apropiación de la naturaleza como lo han hecho siempre para continuar generando beneficios privados y manteniendo los costos ambientales y sociales en el ámbito público. Las élites económicas centroamericanas parecen no estar dispuestas a renunciar a sus privilegios ni a pagar por el uso que hacen del agua y la contaminación que sus actividades extractivas generan.

\section{Los limites del discurso de la GIRH y la gestión por cuenca,}

\section{1. ¿La GIRH, un discurso inaplicable?}

A pesar de la aceptación casi generalizada a la GIRH existen importantes cuestionamientos alrededor de su aplicabilidad e impacto. Para F. Molle la GIRH se puede asimilar a "un concepto nirvana", es decir, un concepto que promete ser "la solución a los problemas de agua de hoy en día" (Molle, 2012b, p.30). Sin embargo, la GIRH ha demostrado sus importantes dificultades para pasar de la teoría a la práctica. En primer lugar, ha sido muy criticada por ser "un conjunto de principios vagos y poco 
realistas" (2012b, p.29). Por lo tanto, se presenta más como un dogma que como un modelo operacional.

Analizando las estrategias y las legislaciones nacionales en materia de agua en Centroamérica, pareciera que en esta región la GIRH incluso como estrategia para la neoliberalización del agua ha fallado ya que la mayoría la mayoría de los marcos normativos no la han incorporado y si bien en algunos países hay estrategias nacionales para la gestión del agua, no hay capacidad técnica ni institucional para aplicar las estrategias y acciones propuestas.

Es así como una de las principales críticas se refiere a su inaplicabilidad (Julien, 2012, p.7). Algunos autores como A. Biswas señalan la dificultad de medir los impactos que puede tener la GIRH ya que no existen parámetros para medir el grado de integración de una cuenca. Para este autor, la GIRH se ha convertido en un "eslogan dominante" difundido a nivel mundial de forma intensiva por las organizaciones internacionales, sin que se haya evaluado realmente su aplicabilidad. Para él es imposible identificar un proceso de gestión del agua "intrínsecamente integrado", por lo que llega a la conclusión de que la GIRH no ha tenido hasta ahora ningún efecto real en el campo (Biswas, 2008, p.13).

Cuando se les cuestionó a las personas entrevistadas, cuáles eran para ellas a escala nacional los casos en donde la aplicación de la GIRH y la gestión por cuenca habían sido exitosos. La mayoría de los entrevistados mencionó dos: 1) la Comisión de Implementación y Desarrollo de la cuenca Arenal-Tempisque (CIDECAT), y 2) la Comisión de Ordenamiento y Manejo de la Cuenca Alta del Río Reventazón (COMCURE). Ambas comisiones fueron creadas por ley y cuentan por lo tanto con recursos específicos para su funcionamiento. Además, se contó con el acompañamiento de organizaciones internacionales como la GWP, la Organización de Estudios Tropicales (OET) y el financiamiento de la UICN.

Es así, como la CIDECAT es muchas veces presentada como un caso exitoso de cooperación institucional (ICE, SENARA y MINAE), a pesar de ser una cuenca "inventada y des-naturalizada" en palabras de Marlon Morúa, geógrafo de la Universidad de Costa Rica y miembro de la Alianza Nacional por el Agua (ANDA) (Comunicación personal, 18 de junio del 2020), esto es debido a que esta cuenca es un trasvase. Esta cuenca nace a raíz de un proyecto de embalse para la generación eléctrica del Instituto Costarricense de Electricidad (ICE) y posteriormente, su caudal es utilizado para el abastecimiento humano y el riego. De esta forma esta cuenca es una obra hidráulica resultado de una decisión política.

Por su parte, la COMCURE, nació como una iniciativa para el ordenamiento de la cuenca del río Reventazón que cubre el 5\% del territorio nacional y por lo tanto recibe el 5\% del canon nacional de agua. Según Gabriela Chaves, presidenta de la Junta Directiva de la COMCURE (Comunicación personal, 5 de noviembre 2020), esta comisión articula representantes del ICE, del AyA, representantes de las 8 represas presentes en la cuenca, las municipalidades y las ASADAS. No obstante, Yamileth Astorga (Comunicación personal, 7 de octubre 2020) llama la atención sobre el hecho de que la COMCURE está más dirigida a la gestión del uso del suelo. Esto debido a que el plan de manejo de la cuenca fue pagado y contratado por el ICE con el objetivo de reducir los sedimentos en la cuenca para que no afectaran las turbinas de los proyectos hidroeléctricos. Por lo que este, no es para ella, un plan de gestión integral ya que no identifica zonas de conservación para proteger las fuentes 
de agua y no se preocupa por la contaminación por agroquímicos de las aguas ya que en la cuenca alta se encuentran importantes actividades agrícolas.

De esta forma, no se puede concluir que estas experiencias generen una verdadera gestión integrada del recurso hídrico, porque están pensadas para garantizar la generación de energía hidroeléctrica y no se preocupan por la protección y contaminación del agua.

Es así como los conceptos y metodologías propuestos por la GIRH son recetas, difíciles de aplicar en la práctica. Es difícil encontrar experiencias que puedan considerarse "ejemplares". A escala local, hemos visto que la GIRH está lejos de ser apropiada por las autoridades nacionales y locales. La falta de claridad de este concepto y de la delimitación de la cuenca no es exclusiva de los actores locales, sino que también llega a los profesionales de las organizaciones internacionales (Biswas, 2008) y los técnicos de los ministerios. En este sentido, el 70\% de los entrevistados a escala local (productores, autoridades indígenas, organizaciones de mujeres, etc.) tuvieron dificultades para identificar los límites de las cuencas en las que residían. Para muchos, este es un concepto "que viene de afuera".

La falta de apropiación de esta noción no es exclusiva de las experiencias estudiadas, los estudios realizados en el África subsahariana por C. Bouquet llegan a la misma conclusión: “¿La cuenca? Este es un concepto que los habitantes del África rural manejan a su manera, según una representación del espacio vital que apenas abarca (...). Es raro, si no imposible, que puedan dibujar en un mapa mental la línea divisoria de aguas que concierne a la comunidad en cuestión" (Bouquet, 2012, p.65).

Por su parte, F. Molle identifica cuatro puntos débiles de la GIRH: 1) la despolitización del agua que conlleva; 2) su propensión a ser desviada por grupos de interés que buscan legitimar sus prácticas; 3 ) la imposición de políticas estandarizadas (recetas) y "buenas prácticas" predefinidas sin tener en cuenta el contexto; y 4) la gran dificultad que se ha encontrado en su aplicación, especialmente en el Sur, debido a importantes incompatibilidades (Molle, 2012a, p.36).

\subsection{La GIRH y la gestión por cuenca un "discurso institucional autorizado"}

El discurso de las comunidades epistémicas del agua es un tipo de "discurso institucional", que constituye "un tipo cuasi ideal de discurso político" (Gobin y Deroubaix, 2011, p.107). Esta categoría de discursos son definidos por A. Krieg-Plaque y C. Oger como "discursos autorizados" (Krieg-Planque y Oger, 2010, p.92), es decir, aquellos discursos que buscan crear legitimidad.

El estudio de los discursos institucionales permite analizar cómo evolucionan las prioridades en las agendas políticas a lo largo del tiempo y, de forma más general, "lo que significa gobernar" (Gobin y Deroubaix, 2011, p.107). Para ello, se estudiaron los textos que se hicieron públicos a través de folletos y documentos de los proyectos de cooperación que se ejecutan desde la UICN, el BID y la misma GWP. Con el fin de demostrar cómo este discurso institucional trata de despolitizar y tecnificar la gestión del agua para invisibilizar los conflictos y contradicciones.

Una primera observación es que el número de documentos producidos es significativo y hemos constatado que los productos de comunicación que emanan de estas organizaciones son de naturaleza muy diversa: hemos identificado folletos, documentos que sistematizan experiencias, informes, notas de prensa y vídeos institucionales. 
El análisis del discurso propuesto por A. Krieg-Planque estudia "las fórmulas" es decir "un conjunto de formulaciones que, por su uso en un momento dado y en un espacio público determinado, cristalizan debates y problemáticas políticas y sociales que estas formulaciones contribuyen a construir al mismo tiempo" (Krieg-Planque, 2010, p.6). Sus estudios se han dedicado al análisis del discurso institucional relacionado con la formula del desarrollo sostenible (Krieg-Planque, 2010, p.6). Este trabajo nos da importantes pistas para entender la fórmula de la GIRH.

A. Krieg-Planque afirma que una fórmula se caracteriza por ser un referente social, es decir, "significa algo para todos" (Krieg-Planque, 2010, p.7), lo cual es el caso de las fórmulas de desarrollo sostenible y de GIRH. S. Ghiotti ha demostrado que el uso creciente de la fórmula de la GIRH en la agenda mundial y en las producciones científicas durante los años 1990 y 2000 es una respuesta a un aparente consenso mundial sobre el hecho de que la GIRH proporciona "la respuesta" a los problemas relacionados con los recursos hídricos (Ghiotti, 2014). La internacionalización de esta fórmula, como explica A. Krieg-Planque en el caso del desarrollo sostenible, reside en el hecho de que cuando "una fórmula circula es porque el uso de la propia expresión constituye una apuesta" y esto muestra el éxito del término (Krieg-Planque, 2010, p.7).

Es así como la fórmula de la GIRH se convirtió en una consigna mundial, una palabra de orden que daba sentido a una serie de instituciones y organizaciones. La GIRH condicionó así la existencia de estructuras, proyectos, acciones, créditos y legitimaba las prácticas (Krieg-Planque, 2010, p.8) de una serie de organizaciones internacionales y de bancos.

Para legitimar el discurso de la GIRH, a nivel internacional, las organizaciones utilizaron una retórica particular: la de la crisis ambiental (Gobin y Deroubaix, 2011, p.110). La GIRH se presenta así como una fórmula que se crea "para abordar la degradación de los recursos hídricos" (Gobin y Deroubaix, 2011, p.110). Es así como en los documentos de proyectos y de programas ligados al agua, se vuelven comunes las siguientes afirmaciones: "Hemos hecho el máximo uso de este precioso recurso" (UICN, 2012a) o "el mundo se enfrenta a importantes desafíos para gestionar equitativamente el agua dulce disponible para una población creciente, al tiempo que intenta detener la pérdida de biodiversidad y hacer frente a los impactos del cambio climático" (UICN, 2012b). Además, estas organizaciones utilizan sistemáticamente imágenes de los posibles impactos que el fracaso en la aplicación de la GIRH puede tener en las comunidades. Las imágenes de las inundaciones, de las personas desplazadas por fenómenos naturales extremos, ilustran las presentaciones, los documentos descriptivos de los proyectos y los folletos.

El análisis de las consignas utilizadas por estas organizaciones nos permite concluir que estas han sido desarrolladas de manera que se mantengan lo suficientemente generales y vagas para ser utilizadas en diferentes territorios sin hacer referencia a las particularidades de cada contexto o país. Y esta es una crítica importante que se le hace a la GIRH, su pretensión de universalidad, ya que fue diseñada para ser aplicable en todos los contextos (Julien, 2012, p.7), sin tener en cuenta las particularidades.

Además la GIRH, al igual que el desarrollo sostenible, es presentada como un "hecho objetivable, cuantificable, medible y cartografiable" (Krieg-Planque, 2010, p.6) que es estudiado y difundido por todo un sistema de expertos vinculados a las profesiones de la gestión del agua. Esta idea de neutralidad y objetividad se ve 
reforzada por la circulación de un lenguaje que pretende ser experto y que moviliza conceptos como el enfoque por ecosistemas, la gobernanza, la adaptación al cambio climático, entre otros. Estos conceptos forman parte de este discurso institucional que se caracterizan por su falta de precisión (Gobin y Deroubaix, 2011). Cuanto más circulan estos conceptos, más pierden su significado.

Por ejemplo, el análisis del discurso de la UICN a través de los proyectos Alianzas, BRIDGE y Adaptación al Cambio Climático muestra que se trata de un discurso circular (Gobin y Deroubaix, 2011) que se basa en tres recursos argumentativos: más participación local, más mecanismos de regulación legal y más capacitación-sensibilización. La retórica desarrollada por esta organización es hueca, ya que utiliza fórmulas preestablecidas y basa su argumentación en la repetición de palabras claves, como participación, GIRH y gobernanza ambiental. Estas fórmulas se perciben de manera positiva y crean aceptación y legitimidad (Gobin y Deroubaix, 2011, p.109).

Para A. Krieg-Planque y C. Oger, dos aspectos parecen esenciales para comprender el discurso institucional. El primero es "la estabilización de los datos y el segundo es la invisibilización de la conflictividad" (Krieg-Planque y Oger, 2010, p.92).

\subsection{Estabilización de datos}

En relación con la estabilización de los datos, estos autores han observado que la producción y la circulación del discurso institucional "obedece a regularidades que reducen la diversidad de enunciados posibles" y esto se materializa en "fenómenos de formulaciones convencionales, de esloganización" (Krieg-Planque y Oger, 2010, p.92). Expresiones como el desarrollo sostenible, el enfoque por ecosistemas y la GIRH "combinan la figuración formal y la indeterminación del referente" (KriegPlanque y Oger, 2010, p.92). Así es como el discurso de estas organizaciones internacionales (ONU, UICN, TNC, WWF) presenta formas "rutinarias" de escritura en un contexto restringido que "está marcado por las agendas sociopolíticas e institucionales que movilizan" (Krieg-Planque y Oger, 2010, p.93).

Otro elemento clave, es que el discurso de la GIRH, como el del desarrollo sostenible o el cambio climático, utiliza nombres propios de eventos (por ejemplo, Cumbre de la Tierra, Río+10, COP 15) para mostrar la trayectoria de un concepto (KriegPlanque, 2010, p.10). El hecho de referirse a las cumbres o reuniones como los lugares en que se producen estos conceptos les da legitimidad, en particular por parte de la comunidad internacional. En el caso del desarrollo sostenible, por ejemplo, se suele citar el "Informe Brundtland" de la Cumbre Mundial sobre la Tierra de 1992 para determinar el origen del concepto. En el caso de la GIRH, los proyectos y los actores entrevistados suelen hacer referencia a la Conferencia Internacional sobre el Agua de Dublín de 1992, en la que se elaboraron los "Cuatro Principios de Dublín", que se convirtieron en su base. La fórmula de la GIRH estaba compuesta por textos claves, que son en realidad relatos, declaraciones y documentos, en los que los promotores de estos proyectos creen que pueden identificar las intenciones iniciales y los fundamentos de la fórmula (Krieg-Planque, 2010, p.9). Es así como se utilizan a menudo estos textos como fuente legítima de la definición y muchas veces son vistos como directrices que hay que acatar. A. Krieg-Planque afirma que estos textos "fundadores" dan consistencia a la fórmula y adquieren un estatus casi de mítico o leyenda (Krieg-Planque, 2010, p.10) que los vuelve casi indiscutibles. 
De esta forma, estos discursos institucionales tienden a utilizar términos vagos con cierto grado de indeterminación y citas que generan autoridad para construir una retórica vacía que trata de fomentar la adhesión a la fórmula que se está difundiendo.

\subsection{La invisibilización de la conflictividad, un discurso sin adversarios}

El segundo elemento clave presentado por A. Krieg-Panque y C. Orger para comprender las particularidades de los discursos institucionales es la invisibilización de la conflictividad. Las organizaciones e instituciones encargadas de difundir estas fórmulas deben cumplir requisitos que a menudo son contradictorios: mantener el crecimiento económico y conservar la naturaleza. Ante esta situación, estas organizaciones tienden a "organizar la polifonía, reducir la disonancia, producir coherencia (...) tienden a borrar las huellas del conflicto y las tensiones internas". Así es como pueden neutralizar la oposición entre la posición de los expertos y el posicionamiento político, "conciliar los intereses de los socios públicos y privados, negar las diferencias de opinión y legitimar el discurso experto" (Krieg-Planque y Oger, 2010, p.93).

El carácter hegemónico de la fórmula de la GIRH no implica su homogeneidad (Krieg-Planque, 2010, p.7). Aunque existe un consenso general a nivel internacional, F. Molle afirma que hay una visión "blanda" y otra visión "dura" de la gobernanza propuesta por la GIRH. El lado "blando" es más gerencial, más centrado en el Estado y considera que el cambio institucional es impulsado principalmente por los encargados de adoptar decisiones con la participación de las partes interesadas, este ha sido el caso en la COMCURE. La parte "dura" se centra más en la sociedad civil, fomenta la creación de plataformas de multi-actores y busca la emancipación de los stakeholders (Molle, 2012b, p.32), esta corriente tuvo mucha influencia en el proyecto de ley por iniciativa popular que organizaciones defensoras del agua presentaron en Costa Rica en el año 2009. Lo que hemos podido observar en las diferentes entrevistas es que los diferentes actores se apropian del enfoque que más les conviene, siempre afirmando que están aplicando medidas de GIRH.

Por otro lado, la definición de GIRH, como ya se ha mencionado, se basa en tres pilares, Eficiencia, Equidad y Medio Ambiente (Molle, 2012b, p.26), los cuales están bastante distanciados entre sí ya que inspiran una amplia variedad de acciones que pueden parecer muchas veces contradictorias. Por ejemplo, en el marco de la eficiencia económica, se fomentan la privatización, mientras que, el principio de equidad, promueve el derecho al agua y la hidrosolidaridad. Estas acciones se presentan a menudo en el discurso como complementarias, ocultando así la contradicción que evidencian. Sin embargo, esto plantea un importante debate que generalmente se borra en los textos de los proyectos y que reside en el hecho de que el agua se define según los "Principios de Dublín" como un derecho, un recurso común y vulnerable, y al mismo tiempo como un bien económico con un valor específico. Esteban Monge de CEDARENA pone en evidencia las tensiones que este tema ha generado en Costa Rica y afirma:

Tanto sectores de izquierda como los de derecha se oponen al principio de Dublín que concibe el agua como un bien económico por diferentes razones. Los sectores de izquierda cuestionan el principio que el que contamina paga porque dicen que es comprar una licencia para contaminar y por otro lado los sectores productivos 
también lo cuestionan porque no quieren pagar (Comunicación personal, 6 de agosto 2021).

En este sentido, A. Krieg-Planque cita como ejemplo la contradicción existente dentro de la definición de "desarrollo sostenible", que fomenta tanto el crecimiento como la conservación, lo que puede compararse con un oxímoron utilizado en el discurso político para "reconciliar lo irreconciliable" (Krieg-Planque, 2010, p.8). Es así como los actores aprovechan estas contradicciones y la amplia variedad de significados entre los "pilares" (Equidad, Eficiencia y Medio Ambiente) de la GIRH para acercarse al pilar que mejor sirva a sus intereses.

Esta importante contradicción se minimiza gracias al "estilo de la formula" que la presenta como un consenso y pide la aceptación, fomentando así la adhesión e inhibiendo el contra-discurso (Krieg-Planque y Oger, 2010, p.11). Cabe señalar que esto revela un proceso de despolitización que se refuerza aún más con la proliferación de un "discurso experto" en detrimento de un discurso político, el cual es universalmente difundido y que "oculta las tensiones y los conflictos inherentes a la vida política" (Gobin y Deroubaix, 2011, p.114).

El discurso de la GIRH establece conceptos suficientemente vagos para permitir la inclusión de actores y la generación de acuerdos (Krieg-Planque, 2010, p.11). Es importante acotar que muchos autores cuestionan que el discurso de la GIRH no hace referencia a la degradación del ambiente resultante de las actividades productivas, sino más bien promueven la adaptación y la convivencia (Gobin y Deroubaix, 2011, p.113). Esto desalienta el debate y lo desideologiza.

Aunque exista esta heterogeneidad, la fórmula de la GIRH trata de borrar la diversidad de categorías y las contradicciones evidentes. Estas fórmulas niegan los conflictos de intereses y neutralizan el conflicto a favor de la gobernanza multi-actores. La importancia que se da a la "democracia participativa" y al papel de las plataformas de multi-actores forma parte de este movimiento de despolitización. La "gobernanza del agua" proporciona una "nueva legitimidad", ya que representa "la celebración del interés general" y refuerza la retórica del universalismo (Krieg-Planque y Oger, 2010, p.94). De esta forma, las fórmulas de GIRH y de la gobernanza desalientan la contradicción y valoran el consenso resultante de los procesos de gobernanza. La eliminación de la conflictividad es una característica del "discurso autorizado" (Krieg-Planque y Oger, 2010, p.94). Es interesante observar como la neutralización de los conceptos ha llevado a la creación de fórmulas como la "responsabilidad social de las empresas" o las "asociaciones público-privadas", que han permitido "desdibujar" la frontera entre el sector público y el privado.

Nos encontramos ante lo que A. Krieg-Planque llama "discurso sin adversarios" que permite la transferencia fluida de estas fórmulas: "el discurso programático internacional se convierte en un discurso nacional legítimo y legitimador" (Gobin y Deroubaix, 2011, p.109; Krieg-Planque y Oger, 2010; Noyer, 2011).

\section{Conclusiones}

Este artículo estudió la genealogía de la formula de la GIRH producida por la comunidad epistémica del agua, comunidad que se estructura en redes de científicos y de 
expertos internacionales reconocidos por su competencia y que ponen al servicio de tomadores de decisión este conocimiento (Haas, 2013, p.351).

La GIRH es así una respuesta occidental, una fórmula transferida desde el Norte a través de proyectos de cooperación a África, Asia y América Latina. Esta se ha convertido en una consigna y su aplicación en una condición de acceso a la ayuda financiera propuesta por el BM. Algunos autores se refieren a la GIRH como un concepto hegemónico (Trottier, 2012; Zeitoum y Warner, 2006) que impone a la cuenca hidrográfica como la unidad ideal de gestión. Sin embargo, la voluntad de crear un territorio de gestión alrededor de la cuenca es una tarea muy difícil, en particular debido a la dificultad de los actores locales (pueblos indígenas) de apropiarse de estos conceptos, a la oposición de las municipalidades a "gestionar territorios que van más allá de sus circunscripciones" y en el caso costarricense, a la negativa de sectores agroexportadores que ven amenazados sus intereses y actividades por la GIRH.

El discurso que se ha desarrollado en torno a la GIRH es un discurso institucional y autorizado que se presenta como neutral, científico, un "hecho objetivo" y apolítico. Sin embargo, los principios de la GIRH son eminentemente políticos, ya que cuestionan la capacidad del Estado para gestionar el agua y promueven formas de gobernanza que incorporan a una gran diversidad de actores. Además, se le asigna al agua un valor económico, lo que ha generado resistencia en una gran diversidad de actores por razones e intereses muy divergentes.

El análisis de los proyectos de cooperación que implementan la GIRH en Costa Rica, evidencia que el discurso de la GIRH es vago, repetitivo, indeterminado y "rutinario" buscando así convertirse en un eslogan irrefutable que encubra el conflicto. Esto con el fin de convertirse en "un discurso sin adversarios" (Krieg-Planque, 2010, p.7) que no busca por lo tanto poner en duda el modelo de desarrollo extractivista hegemónico sino convivir con él.

En Centroamérica, la aplicación de la GIRH no ha sido exitosa por un lado por la falta de legislaciones que incorporen estos principios y por otro lado por la falta de capacidad institucional para ejecutar las pocas acciones que se han desarrollado (reformas constitucionales, planes nacionales del GIRH, entre otros). Además, existen importantes resistencias de los sectores económicos y empresariales. En Costa Rica, la GIRH a pesar de promover la gobernanza neoliberal del agua es vista como una amenaza por los sectores ligados a la agricultura de exportación, los cuales han realizado un importante lobby para evitar la aprobación de leyes que quieran regular y ordenar al sector hídrico. En este sentido, se puede concluir que las sociedades centroamericanas, son el resultado de una larga historia de actividades extractivas que han generado lógicas muy arraigadas de despojo y de acumulación de la riqueza. La región está así, marcada por la desigualdad y por la apropiación de la naturaleza. Este complejo contexto puede explicar porque particularmente los principios de participación y de dotar al agua de un valor económico pueden verse como amenazas para grupos hegemónicos que han hecho un uso indiscriminado del agua, sin negociar con otros usuarios y sin hacerse responsables del daño ambiental que han provocado. Podemos así concluir que las élites económicas y políticas han beneficiado de permisibilidad e impunidad por parte de los gobiernos del Istmo por lo que no requieren encubrir sus actividades con discursos como el de la GIRH para así generar apoyos o para reducir la conflictividad social. 


\section{Referencias}

Acosta, A. (2011). Extractivismo y neoextractivismo: Dos caras de la misma maldición. En Grupo permanente de trabajo sobre alternativas al desarrollo (Ed.), Más allá del desarrollo (pp. 83-118). Quito: Fundación Rosa Luxemburg / Abya Yala.

Balibar, R. (1991). Le colinguisme. París: PUF.

Bengoa, J. (2007). La emergencia indigena en América Latina. Santiago de Chile: Fondo de Cultura Económica.

Biswas, A. K. (2008). Integrated Water Ressources Management: Is it's Working? Water Ressources Developpement, 24(1), 5-22.

Bouquet, C. (2012). La GIRE: Un modèle difficile à transférer en Afrique subsaharienne. En F. Julien (Dir.), La gestion intégrée des ressources en eau en Afrique subsaharienne: Paradigme occidental, pratiques africaines (pp. 55-73). Québec: Presses de 1'Université du Québec.

Brun, A., y Lasserre, F. (2006). Politiques de L'Eau: Grands Principes et Réalités Locales. Québec: Presses de l'Université du Québec.

Descroix, L. (2012). Le bassin versant, une unité de gestion des eaux idéale pour l'Afrique sunsaharienne? En F. Julien (Dir.), La gestion intégrée des ressources en eau en Afrique subsaharienne: Paradigme occidental, pratiques africaines (pp. 77-102). Québec: Presses de l'Université du Québec.

Ghiotti, S. (2006). Les Territoires de l'eau et la décentralisation. La gouvernance de bassin versant ou les limites d'une évidence. Développement durable et territoires. Économie, géographie, politique, droit, sociologie, Dossier 6. https://doi.org/10.4000/developpementdurable. 1742

Ghiotti, S. (2007). Les territoires de l'eau: Gestion et développement en France. París: CNRS.

Ghiotti, S. (2014). Le bassin transfrontalier. Emergence, contruction et intinéraire d'un concept. Regions \& Cohesion, 4(2).

Gobin, C., y Deroubaix, J.-C. (2011). L'analyse du discours des organisations internationales. Un vaste champ encore peu exploré. Mots. Les langages du politique, $n^{\circ} 94(3), 107-114$.

Gros, C. (1998). Identidades indias, identidades nuevas. Algunas reflexiones a partir del caso colombiano. Revista Mexicana de Sociología, 60(4), 187-207.

Gudynas, E. (2009). Diez tesis urgentes sobre el nuevo extractivismo. En VV AA, Extractivismo, politica y sociedad (pp.187-225). Quito: CAAP (Centro Andino de Acción Popular) / CLAES (Centro Latinoamericano de Ecología Social).

Gudynas, E. (2013). Extracciones, extractivismos y extrahecciones. Un marco conceptual sobre la apropiación de recursos naturales. Observatorio del Desarrollo, 18, 1-17.

GWP (Global Water Partnership). (2000). La gestion intégrée des ressources en eau. TAC Background Paper n.4. Recuperado de https://www.gwp.org/globalassets/global/toolbox/publications/background-papers/04-integrated-water-resources-management-2000-french.pdf

Haas, P. (2013). Epistemic Communities. En J. Krieger (Ed.), The Oxford Companion to Comparative Politics (vol. 1, pp. 351-359). Oxford: Oxford University Press.

Hernández-Ulate, A. H.; López-Ramírez, A. L., y Jimenez-Elizondo, A. (2009). Gobernabilidad e instituciones en las cuencas transfronterizas de América Central y México. San José de Costa Rica: FLACSO Costa Rica.

Julien, F. (2012). L'eau à la crise mondiale, solution mondiale? En F. Julien (Dir.), La gestion intégrée des ressources en eau en Afrique subsaharienne: Paradigme occidental, pratiques africaines (pp. 1-14). Québec: Presses de l'Université du Québec. 
Krieg-Planque, A. (2010). La formule "développement durable": Un opérateur de neutralisation de la conflictualité. Langage et société, 134(4), 5-29. https://doi.org/10.3917/ls.134.0005

Krieg-Planque, A., y Oger, C. (2010). Discours institutionnels.Perspectives pour les sciences de la communication. Mots. Les langages du politique, (94), 91-96. https://doi.org/10.4000/mots. 19870

Martínez Alier, J. (2005). El ecologismo de los pobres. Conflictos Ambientales y lenguajes de valoración. Barcelona: Icaria.

Molle, F. (2012a). La gestion de l'eau et les apports d'une approche par la political ecology. En D. Gautier y T. A. Benjaminsen (Dirs.), L'approche Political Ecology: Pouvoir, savoir, environnement (pp. 219-240). París: Quae.

Molle, F. (2012b). La GIRE: Anatomie d'un concept. En F. Julien (Ed.), Gestion intégrée des ressources en eau: Paradigme occidental, pratiques africaines (pp. 23-53). Québec: Presses de l'Université du Québec.

Noyer, J. (2011). Alice Krieg-Planque: La notion de "formule" en analyse du discours. Études de communication, 35(2), 208-211.

ONU (Organización de las Naciones Unidas). (1992). Action 21: Chapitre 18. Protection des ressources en eau douce et de la leur quantité: Application d'approches intégrées de la mise en valeur, de la gestion et de l'utilisation des ressources en eau. Recuperado de $\mathrm{http} / /$ www.un.org/french/ga/special/sids/agenda21/action18.htm

Ostrom, E. (2010). Gouvernance des biens communs, pour une nouvelle approche des ressources naturelles. Bruselas: De Boeck.

Rahaman, M. M., y Varis, V. (2005). Integrated Water Ressources Management: Evolution, Prospects and Future Challenges. Sustainability, 1(1), 15-21.

Rodríguez Echavarría, T. (2014). Gouverner l'environnement dans des régions frontalières. Coopération et conflits dans les bassins du fleuve San Juan (Costa Rica-Nicaragua) et du flueve Sixaola (Costa Rica-Panama). Tesis de Doctorado en Geografía, Paris 7- Diderot.

Rodríguez Echavarría, T. (2018). Policy brief: Una Agenda para el Agua. San José de Costa Rica: CIEP-UCR.

Rodríguez Echavarría, T.; Obando, A., y Acuña, M. (2018). Entender el extractivismo en regiones fronterizas. Monocultivos y despojo en las fronteras de Costa Rica. Sociedady Ambiente, (17), 165-200.

Rodríguez-Echavarría, T., y Prunier, D. (2020). Extractivismo agrícola, frontera y fuerza de trabajo migrante: La expansión del monocultivo de piña en Costa Rica. Frontera Norte, Revista Internacional de frontera, territorios y regiones, 32(25), Epub 10. http://dx.doi.org/10.33679/rfn.v1i1.1983

Grupo Interagencial del Agua. (2009). Estrategia Centroamericana para la Gestión Integrada de Recursos Hídricos. SICA.

Trottier, J. (2012). L'avènement de la gestion intégrée des ressources en eau. En A. Brun y F. Lasserre (Eds.), Gestion de l'eau: Approche Territoriale et Institutionnelle (pp.179198). Québec: Presses Universitaires de Québec.

Ugarte Jiménez, O. (2020). Acceso al agua se convierte en un derecho humano en Costa Rica. Semanario Universidad, 5 de junio. Recuperado de https://semanariouniversidad.com/pais/acceso-al-agua-se-convierte-en-un-derecho-humano-en-costa-rica/

UICN (Unión Internacional para la Conservación de la Naturaleza). (2012a). Adaptación basada en ecosistemas, mejorando los medios de vida y la gobernanza de agua en Mesoamérica. UICN. 
UICN (Unión Internacional para la Conservación de la Naturaleza). (2012b). H2O Compartir, consumir y administrar el agua de manera justa es adaptarse al cambio climático. Proyecto Buena gestión del agua para la adaptación al cambio climático. UICN.

UICN (Unión Internacional para la Conservación de la Naturaleza). (2012c). Programa Mundial del Agua: Agua para la gente y la naturaleza. UICN. Recuperado de https://www.iucn.org/about/work/programmes/water/

UICN (Unión Internacional para la Conservación de la Naturaleza). (2012d). Bridge: Construyendo diálogos y buena gobernanza del agua en ríos. UICN, Oficina Regional de Mesoamérica.

Weinstein, O. (2013). Comment comprendre les "communs": Elinor Ostrom, la propriété et la nouvelle économie institutionnelle. Revue de la régulation. Capitalisme, institutions, pouvoirs, (14). Recuperado de http://regulation.revues.org/10452

Zeitoum, M., y Warner, J. (2006). Hydro-hegemony a framework for analysis of transboundary water conflicts. Water Policy, 8(5), 435-460. 